\title{
DETRATORES E DEFENSORES DA IMIGRAÇÃO ITALIANA PARA O BRASIL: O DECRETO PRINETTI DE 1902 E A EXPOSIÇÃO MUNDIAL DE 1906
}

\author{
Giovani Balbinot ${ }^{1}$
}

\section{A imagem do Brasil como destino para emigração}

É correto afirmar que o Brasil representou um dos principais destinos da emigração italiana, assim como o elemento imigrante italiano delineou-se como um dos principais elementos imigratórios e constituintes da população brasileira. Segundo os dados italianos, entre 1876, ano em que iniciou-se a contabilidade dos expatriados, até 1975, as cifras de emigrantes com destino ao Brasil alcançavam aproximadamente um milhão e meio de indivíduos. Por sua vez, a estatísticas dlo país de chegada contam, entre o período de 1870 a 1975, um milhão e seiscentos mil imigrantes estabelecidos em todo o território nacional - como podemos observar, cifras não distantes da italiana.

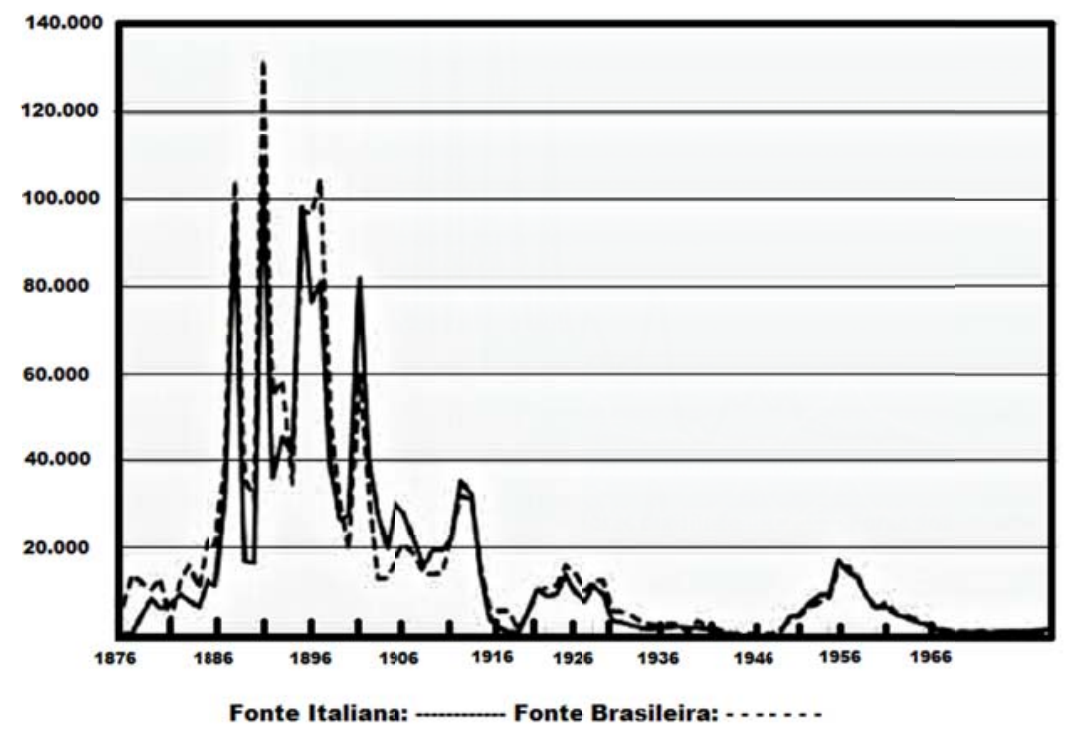

Gráfico 1: Consistenza dell'emigrazione italiana in Brasile secondo le statistiche dei due Paesi di partenza e di arrivo (1876-1975)².

Comparando os dados relativos a duas fontes estatísticas, do país de partida e do destino de chegada, podemos observar, inicialmente, uma incisiva discrepância, geralmente positiva, entre os dados gravados no Brasil e os da fonte italiana. Esta

1 Doutorando em História pela Universidade de Passo Fundo, bolsista CAPES; e-mail: <giovanibalbinot88@gmail.com>.

${ }^{2}$ Fonte: BIRINDELLI; BONIFAZI, 2011, p. 493 apud per l'Italia vedi gráfico n. 1, per il Brasile dati pubblicati in Levy (1974) e dall'Instituto Brasileiro de Geografia e Estatística. 
diferença reflete fatores não detectados pelas autoridades italianas, associadas com partidas de portos estrangeiros, especialmente dos portos franceses, os casos de pessoas empregadas no navio durante a travessia e, por fim, entradas ocorridas da reemigração, especialmente advindos da Argentina. Entretanto, o fato que mais nos interessa neste estudo consiste na alternância de altos e baixos no fluxo e/imigratório, substancialmente atribuível aos acontecimentos políticos e econômicos ocorridos nos dois países. Deste modo, compreendemos que estas extremadas variações na dimensão do fluxo e/imigratório entre Itália/Brasil ocorreram, por um lado, pela imagem construída do Brasil nos países fornecedores de emigrantes, no caso a Itália, $e$, pelo outro, através da legislação que promovia ou dificultava o deslocamento populacional transatlântico.

A partir desta compreensão, delineamos que a imigração italiana para o Brasil produziu, durante o final do século XIX e o início do século XX, uma abundante coleção de narrativas, discursos e debates sobre a realidade encontrada pelos imigrantes em suas novas terras. Viajantes, políticos, intelectuais, jornalistas, e mesmo os relatos dos próprios imigrantes, ajudaram no desenvolvimento das políticas públicas, tanto italianas, quanto brasileiras, que forneceram a legislação diretora deste processo de deslocamento populacional.

Dentre os inúmeros escritos que compõem este contexto, a obra Al Brasile, de Alfonso Lomonaco e L'Europa alla conquista dell'America Latina, de Ferrúcio Macola são deveras importantes, pela repercussão que alcançaram e também por sua importância como fontes históricas para a compreensão dos debates acerca da e/imigração italiana para o Novo Mundo. Publicadas, respectivamente em 1889 e 1894, as obras caracterizam-se pelo seu olhar de aguda crítica ao Brasil. Buscando um embasamento dito cientifico, com visões racistas e etnocêntricas, ilustram as condições insalubres do clima, das cidades, do trabalho e da higiene para então introduzir-se na condição de pobreza dos imigrantes italianos aqui estabelecidos.

Neste sentido, as descrições e análises de Lomonaco e Macola, mesmo a partir de perspectivas distintas, desaconselham decididamente a emigração para o Brasil. Alfonso Lomonaco, através de uma visão científica, que beirava o darwinismo social e a hierarquização das raças, acreditava que tanto o meio quanto o povo seriam capazes de corromper os italianos, tornando-os perniciosos como os brasileiros. Por sua vez, Ferrúcio Macola considerava a hipótese da emigração, entretanto, desaconselhava que esta ocorresse dirigida para a América do Sul, em especial ao Brasil. Criticava acidamente o governo italiano pela sua incapacidade de tutelar o processo emigratório italiano, permitindo que este dirigisse seu fluxo para as Américas $e$ não para um território que comportasse maior desenvolvimento econômico do elemento italiano, desperdiçando a presumida possibilidade de estabelecer lucrativas redes comerciais com estas "colônias" no Exterior. Contudo, ambos consentiam a situação do emigrante italiano e sua relação com o autóctone brasileiro. Apelidados pretensiosamente de "carcamanos", os italianos, na visão dos dois autores, eram hostilizados e humilhados em território brasileiro, negando-os condições minimamente dignas de trabalho. Conforme retrata Constantino, ambas as publicações ridicularizam o Brasil e os brasileiros, considerados representantes de uma raça inferior, e narram um país de males e de maus, para onde os italianos não deveriam emigrar em hipótese alguma. 
Mesmo rendendo-se as belezas naturais do Rio de Janeiro e da Baía de Guanabara, principal cartão postal do Estado e, talvez, do Brasil, ambos os autores retratam uma realidade em alto grau desumana quando abordam realidade da cidade e dos imigrantes nela instalados. A vitrine do Brasil, como estes conceituam a cidade, era povoada por indivíduos de qualidade moral duvidosa, jogadores inveterados, imorais, preguiçosos, promíscuos, corruptos, vaidosos, irresponsáveis, perdulários e, ademais, alimentam-se de modo deplorável. Tudo isto em uma cidade "pestilenta", atormentada por um clima onde o calor abrasa e a umidade sufoca. Escassa em lugares "civilizados", praças, palácios e monumentos. ${ }^{3}$

Entre outros relevantes detratores da imigração que buscavam delinear a realidade do italiano nas fazendas de café, encontramos Oreste Ristori. Também imigrante, o anarquista toscano, estabelecido no Brasil a partir de 1904, após passar pela Argentina e pelo Uruguai, prossegue seu trabalho político e jornalístico, notadamente através de seu jornal anarquista La Battaglia. Com Contro l'immigrazione al Brasile, publicado 1906 no Brasil e em 1907 na Itália, Ristori propunha duas questões: o despertar de uma consciência política entre os imigrantes italianos estabelecidos no Brasil e, também, como um alerta para aqueles que, ainda na península, cogitavam a emigração. Conforme afirma Beneduzzi "[...] l'anarchico toscano afferma che il fenommeno migratorio nasce da um inganno: al lavoratore italiano viene offerta la cuccagna, quando in verità viene a trovarsi in una condizione peggiore di quella di partenza."

Ou seja, aos já aqui estabelecidos, a obra de Ristori buscava o despertar de uma consciência política e de um movimento de classe que viesse a promover uma luta para a mudança das condições subalternas e de maus tratos. Aos ainda em solo italiano, buscava dissuadir da ideia de emigrar para o Brasil.

Frente a este contexto e os relatos a partir dele produzidos, em busca do real conhecimento da situação, o Commissariato dell'Emigrazione da Itália destacou ao Brasil dois agentes, Ildo Zattery e Adolpho Rossi, para verificar a realidade encontrada pelos egressos da península itálica. O primeiro foi incumbido de inspecionar a situação dos imigrantes radicados em Minas Gerais e no Espírito Santo. Ao segundo coube examinar a situação dos italianos nas fazendas de café paulista. O relatório elaborado por Adolpho Rossi obteve especial importância, tanto pelo debate que promoveu na imprensa italiana e brasileira, quanto pelo diagnostico apresentado

\footnotetext{
${ }^{3}$ CONSTANTINO, Núncia Santoro de. Os males e os maus: desvãos de textos sobre a emigração italiana para o Brasil. Universidade de Caxias do Sul (UCS), MÉTIS: história \& cultura, v. 4, n. 8, p. 11-35, jul./dez. 2005, p.31-33.

${ }^{4} \mathrm{Em}$ tradução livre: "[...] o anarquista toscano afirma que o fenômeno migratório nasce de um engano: ao trabalhador italiano é oferecido a cocanha - fartura, quando na verdade ele encontra uma condição pior daquela a qual pertencia". BENEDUZI, Luís Fernando. Schiavi bianchi e prigionieri delle fazendas: una lettura del processo migratorio in quanto spazio di morte e distruzione dell'umano. In: CANNAVACCIUOLO, Margherita; PALADINI; Ludovica, ZAVA, Alberto. L'America Latina: La violenza e Il racconto. Venezia: Edizioni Ca'Foscari, 2012, -.107-127, p. 34.
} 
sobre o resultado da imigração italiana para o Brasil e as repercussões diretas deste panorama para o fluxo populacional Itália/Brasil e no governo italiano.

Conforme matéria titulada "Immigração Italiana em São Paulo", veiculada no jornal Correio Paulistano na terça-feira 10 de junho de 1902, as notícias que chegavam de Roma e eram então publicadas nas seções telegráficas dos jornais de São Paulo e do Rio de Janeiro versavam que o relatório que o jornalista Adolpho Rossi apresentara ao Comissariado de Imigração da Itália delineava o pior cenário possível sobre a vida dos peninsulares no Brasil: "O Sr. Rossi, no seu relatório, frisou, com as cores mais negras, o que de ruim, em sua rápida passagem, pode lobrigar sobre as condiçóes moraes e materiaes em que se encontram os immigrantes neste Estado, ou o que, por informantes suspeitos, lhe foi narrado." ${ }^{5}$ Um sumário do relatório elaborado por Rossi, tido como um conceituado e importante jornalista italiano, foi amplamente divulgado pela mídia italiana, especialmente pelos jornais Corrieri della Sera, Secolo e Giornale d'Italia ${ }^{6}$. As informações apresentadas pelo enviado delineavam um quadro absolutamente precário das condições dos italianos emigrados para as terras brasileiras, embora reconhecesse que aproximadamente 5.230 italianos em São Paulo já apresentavam-se como proprietários rurais. Rossi descrevia a ideia da emigração para o Brasil como a pior da vida dos emigrantes peninsulares. Apresentava o Brasil, e mais pontualmente as fazendas paulistas, como uma terra insalubre e bárbara, assolada pela falta de higiene e pestilência, onde as relações de trabalho eram permeadas por um tratamento semelhante ao dispensado ao cativo africano, liberto havia poucas décadas, tanto no que tangia a humilhações e hostilidades físicas e psicológicas, quanto em relação à falta de liquidação dos empenhos financeiros devidos aos imigrantes após os trabalhos na cafeicultura. Conforme noticiado no Correio Paulistano,

O Brasil inteiro, na opinião do Sr. Adolpho Rossi, é uma immensa hecatombe de italianos, os fazendeiros, na sua quase totalidade uma categoria de escravagistas ferozes, que exploraram o trabalho alheio, e não satisfazem os seus compromissos, e remata o seu digno relatório com affirmativa de que a emmigração italiana para o Brasil é um crime. ${ }^{7}$

Entretanto, cabe ressaltar que, tanto o relatório de Adolpho Rossi, quanto as críticas promovidas pela imprensa italiana sobre as condições dos emigrados em São Paulo, não passaram alheias e despercebidas no Brasil, gerando protestos veementes por parte da mídia impressa paulista e das autoridades governamentais relacionadas à imigração.

Sobre a fundamentação de críticas tão acrimoniosas, estas não eram em todo errôneas. Os imigrantes italianos, oriundos de diferentes regiões da Itália, deparam-se

\footnotetext{
${ }^{5}$ Jornal Correio Paulistano, São Paulo, 10 de junho de 1902. Ano 1902 - Arquivo 13937. Disponível em: http://memoria.bn.br/hdb/periodico.aspx. Acesso em 01/02/2017.

${ }^{6}$ Jornal Correio Paulistano, São Paulo, 22 de junho de 1902. Ano 1902 - Arquivo 13949. Disponível em: http://memoria.bn.br/hdb/periodico.aspx. Acesso em 01/02/2017.

7 Jornal Correio Paulistano, São Paulo, 13 de junho de 1902. Ano 1902 - Arquivo 13940. Disponível em: http://memoria.bn.br/hdb/periodico.aspx. Acesso em 01/02/2017.
} 
no Brasil com relações econômicas, sociais e culturais há séculos estabelecidas nestes espaços. A partir do fato de que os imigrantes foram inseridos no processo produtivo e no espaço social antes ocupado pelo escravo africano, embora em condição jurídica não similar à do cativo, este era visto e percebido pelos "senhores do café" da mesma maneira que suas antigas propriedades servis. A imigração italiana era entendida, a partir deste prisma, como a solução para o problema nacional. Uma vez que a produção cafeeira delineava-se como o motor econômico nacional, os italianos deveriam reestabelecer a dominação sobre o trabalho através da manutenção do baixo custo com a mão de obra e a rentabilidade da produção cafeeira. Desta forma, a figura do imigrante italiano, ao ocupar os mesmos espaços físicos produtivos $e$ sociais dos escravos, fora, muitas vezes, percebida e mesmo tratada como a do novo negro ou do novo escravo branco. Esta percepção do imigrante era reforçada pela circunstância do financiamento das viagens transatlânticas por parte do Estado brasileiro e das diversas formas de endividamento contraídas pelos egressos da península itálica que contribuíam no processo de subordinação desta nova mão de obra.

Dentro desse contexto, a transição do trabalho escravo africano para o trabalho livre imigrante torna-se componente essencial para a compreensão da colossal diferença entre o horizonte de expectativas carregadas através do Atlântico pelos italianos e a realidade encontrada por estes nos eitos das fazendas de café paulistas. $\mathrm{O}$ fato do imigrante ter assumido o espaço produtivo antes ocupado pelo escravo africano, mesmo que este processo tenha se transformado sucessiva $e$ consubstancialmente conforme avançavam as negociações entre italianos e "baróes do café", promoveu a sobreposição dos dois sujeitos sociais. Fato este agravado pela preferência da imigração subsidiada, que criava uma forma de vinculação por dívida e dependência, desejada pelo fazendeiro, que obrigava os imigrantes a permanecerem nas propriedades onde haviam sido contratados, ainda que em difíceis condições de trabalho e sobrevivência, quase análogas a do escravo ${ }^{8}$.

$\mathrm{O}$ jornal Correio Paulistano elaborou um inquérito a respeito das condições dos imigrantes em São Paulo, publicando em uma seção especial dedicada ao tema dos italianos algarismos que delineavam as boas condições em que encontravam-se as colônias italianas neste Estado, cuja grande parte da riqueza econômica, social $e$ política explicava-se "pela intelligencia e operosidade de seus membros, cujo trabalho tem fecundado a riqueza e o progresso do nosso Estado." ${ }^{9}$ Em uma sequência de publicações, foram expostos algarismos e comentários que procuravam evidenciar a conjuntura profícua dos imigrantes italianos em São Paulo, com dados referentes a bens imóveis adquiridos, hipotecas realizadas sobre imóveis, casas comerciais estabelecidas, industrias constituídas, entre outras informações, como as relativas ao comércio Itália/Brasil, argumentando que se "a emmigração italiana para o Brasil é um crime, como, no emtanto, de quarenta a cincoenta milhões são annualmente

${ }^{8}$ BENEDUZI, Luís Fernando. Alteridade e estranhamento: a figura do "novo negro" na imigração italiana no Brasil. Universidade de Caxias do Sul (UCS), MÉTIS: história \& cultura - v. 13, n. 27, p. 71-90, jan.jun. 2015.

9 Jornal Correio Paulistano, São Paulo, 10 de junho de 1902. Ano 1902 - Arquivo 13937. Disponível em: http://memoria.bn.br/hdb/periodico.aspx. Acesso em 01/02/2017. 
remettidos pelos colonos para a Italia, e a importação do commercio italiano chegou até hoje a 16 milhoes de liras por anno?"10

Além destes dados, também foram questionadas as informações contidas no relatório elaborado pelo jornalista Adolpho Rossi, que ambos os jornalistas destinados para avaliar a condição dos emigrados em solo brasileiro foram designados "antes recompensas a serviços políticos, que interesse pela emigração", argumentando também que Adolpho Rossi esteve em solo brasileiro pelo breve período de três meses, sendo "verdadeiramente incrível, que em tão curto lapso de tempo, se possa apresentar um tal trabalho conscienciosamente", de forma que uma "peça tão rica de observações e conclusões que um diplomata hábil e acostumado as artimanhas do officio, teria a muito custo pensado que fosse possível conseguir tanto material e tanta sabedoria em dezenas de annos de estudo." 11

As críticas ao relatório de Rossi não cessavam na questão do conciso período de tempo em que este foi elaborado, estendendo-se também à circunstância de que era potencialmente impossível que, em três meses, um correspondente, por mais hábil que fosse, pudesse visitar $e$ analisar um estado cuja extensão é análoga à da Itália, e realizar assim uma adequada relação das impressões dos lugares, compreendidas as fazendas que são distantes dos núcleos e centros de população.

[...] o Sr. Rossi conversou aqui na nossa capital unicamente com o seu Cônsul e no interior com os vice-consules, mantendo-se sempre afastado de todo o mundo, dando um ar mysterioso a sua missão, quando muito outro devera ser o seu procedimento, quando devera ter se approximado das pessoas que lhe pudessem prestar esclarecimentos e facilitarlhe meios de visitar, examinar as nossas cidades, afim de formar juízo seguro e poder leal e conscienciosamente desempenhar a sua incumbência. ${ }^{12}$

Desta forma, eram questionadas as conclusões apresentadas sobre condições sanitárias $e$ de higiene das colônias italianas, as humilhações $e$ hostilidades dispensadas aos imigrantes e o descumprimento dos empenhos financeiros devidos aos colonos $^{13}$. Nesse contexto, fora também questionada, de forma energética $e$ constante, as motivações e intenções que regeram a ação de Rossi e dos envolvidos no trabalho de pesquisa e elaboração do seu relatório, argumentando que "pela exiguidade do tempo, o Sr. Rossi não terá podido visitar todas as fazendas e aquellas que ele visitou talvez fossem indicadas por pessoas que tem interesse em prejudicar o

\footnotetext{
10 Jornal Correio Paulistano, São Paulo, 13 de junho de 1902. Ano 1902 - Arquivo 13940. Disponível em: http://memoria.bn.br/hdb/periodico.aspx. Acesso em 01/02/2017. Os dados mencionados encontram-se publicados nas edições posteriores, identificadas nos arquivos 13937 a 13949.

${ }^{11}$ Jornal Correio Paulistano, São Paulo, 13 de junho de 1902. Ano 1902 - Arquivo 13940. Disponível em http://memoria.bn.br/hdb/periodico.aspx. Acesso em 01/02/2017.

12 Jornal Correio Paulistano, São Paulo, 13 de junho de 1902. Ano 1902 - Arquivo 13940. Disponível em http://memoria.bn.br/hdb/periodico.aspx. Acesso em 01/02/2017.

13 Jornal Correio Paulistano, São Paulo, 22 de junho de 1902. Ano 1902 - Arquivo 13949. Disponível em http://memoria.bn.br/hdb/periodico.aspx. Acesso em 01/02/2017.
} 
Estado de São Paulo, como centro de grande emmigração" ${ }^{14}$. O Correio Paulistano, em edição de 13 de junho de 1902, argumentava:

É um crime sim, mas que resultados deliciosos dá esse crime! Ah, si certos repórteres se lembrassem em tempos das boas normas do seu officio, não cahiriam tão desastradamente nos bestialógicos do absurdo quando o pavor ou a cegueira dos partidos dominantes os elevam a cargos de responsabilidade superior as próprias forças. ${ }^{15}$

Não obstante este intenso debate promovido pelas informações apresentadas por Adolpho Rossi, seguiu-se ainda um informativo intitulado Le condizioni dell'Emmigrazione agrícola in Ribeirão Preto, fruto da compilação da Comissão Geral de Emigração através de diversas referências às denúncias de dificuldades levadas por imigrantes italianos às suas representações diplomáticas no Brasil. De acordo com Anna Maria Birindelli e Corrado Bonifazi, "Il Commissariato dell'Emigrazione invia ispettori sia nelle colonie italiane sia nelle fazendas: ne emerge un quadro preoccupante sulle condizioni di vita e sugli episodi di sfruttamento della manodopera, per cui il governo italiano emana, nel Marzo del 1902, il decreto Prinetti-Bodrio."16

\section{O Decreto Prinetti e suas consequências para o fluxo emigratório Itália/ Brasil}

Protestos sobre espaços ocupados pelos imigrantes nas fazendas de café paulistas, episódios de sobreposição entre as figuras dos cativos africanos e dos trabalhadores peninsulares, ocorrências de subalternidades dos trabalhadores italianos $e$ as constantes disputas políticas e ideológicas sobre o controle ou não do processo de emigração efervesceram; não apenas em denúncias promovidas por imigrantes aos Consulados Italianos ou narrativas e discussões entre defensores e detratores da emigração, mas também produziu-se uma legislatura acerca deste processo, em especial uma nova normativa do Reino da Itália, conhecida como Decreto Prinetti, de 1902, que estabelecia a proibição da emigração subsidiada para o Brasil ${ }^{17}$.

Após múltiplos relatórios consulares e mesmo as constantes reclamações diretas de italianos emigrados relativos ao tratamento recebido por estes nas fazendas cafeeiras analisados anteriormente, o governo italiano estabelece o chamado Decreto Prinetti,

\footnotetext{
14 Jornal Correio Paulistano, São Paulo, 22 de junho de 1902. Ano 1902 - Arquivo 13949. Disponível em http://memoria.bn.br/hdb/periodico.aspx. Acesso em 01/02/2017.

15 Jornal Correio Paulistano, São Paulo, 13 de junho de 1902. Ano 1902 - Arquivo 13940. Disponível em http://memoria.bn.br/hdb/periodico.aspx. Acesso em 01/02/2017.

${ }^{16}$ Em tradução livre: "a Comissão de Imigração envia inspetores, tanto nas colônias italianas quanto nas fazendas: assim emerge um quadro preocupante das condições de vida e dos episódios de exploração da força de trabalho, pelos quais o governo italiano emite, em março de 1902, o decreto PrinettiBodrio". BIRINDELLI, Anna Maria; BONIFAZI, Corrado. L'emigrazione italiana verso il brasile: tendenze e dimensioni (1870-1975). In: SOUSA, Fernando de, Et al. (Org.). Um Passaporte para a Terra Prometida. Porto: CEPESE/Fronteira do Caos, 2011, p. 493-517, p. 503.

${ }^{17}$ TRENTO, Ângelo. Do outro lado do Atlântico: um século de imigração italiana no Brasil. São Paulo: Ed. Nobel, Instituto Italiano de Cultura, 1989.
} 
proibindo a emigração subsidiada para o estado de São Paulo. Conforme David Aliano, o impacto desta lei

[...] was considerable: just one year before its enactment, 59,869 italians had entered Brazil, while only 12,970 entered in 1903, the first year in which the law was in full effect. In 1913 only 16 per cent in coming immigrants were of Italian origin, a distant third place behind Portuguese and Spanish migrants, while the United States of America emerged in these years as the preferred destination of Italian emigrants to the Americas. ${ }^{18}$

O chamado Decreto Prinetti que, em verdade, nunca foi um decreto, mas, sim, tratou-se de uma portaria expedida pelo Comissariado Italiano da Emigração, assinada em 26 de março de 1902 pelo então comissário-geral Luigi Rodio, sendo Giulio Prinetti Ministro de Exterior. Assim, o Decreto Prinetti definia a suspensão da licença especial conferida a quatro companhias de navegação $e$ a um pequeno "vetor" para realizar transporte transatlântico gratuito de emigrantes italianos para o Brasil, além de coibir as operaçóes de recrutamento por parte dos agentes contratados por estas companhias e proibir a emigração subsidiada para o Brasil. Entretanto, cabe ressaltar que este decreto de forma alguma proibia a emigração espontânea de italianos, apenas limitava-se a extinguir a emigração subvencionada e colocava o Brasil, especialmente São Paulo e Rio Grande do Sul, no mesmo plano de outros países para onde direcionavam-se grandes fluxos emigratórios, como Estados Unidos e Argentina ${ }^{19}$.

Contudo, devemos considerar que o fluxo emigratório italiano para o Rio Grande do Sul, no contexto de Decreto Prinetti, em 1902, não era subvencionado. Deste modo, resta-nos analisar quais as questões que levaram o governo Borges de Medeiros a participar da Exposição Universal de 1906 na cidade de Milão. Sustentamos, assim, as hipóteses de que o PRR (Partido Republicano Rio-Grandense) buscava, por um lado, a revogação do Decreto Prinetti e, por outro, a construção de uma imagem sobre o estado no panorama italiano diferenciando-se da realidade brasileira e paulista que gerou o estabelecimento do decreto, ambos com o objetivo final de ampliar o fluxo emigratório italiano para a colonização rio-grandense.

\footnotetext{
${ }^{18}$ Em tradução livre: "[...] foi considerável: apenas um ano antes de sua promulgação, 59,869 haviam entrado no Brasil, enquanto apenas 12,970 o primeiro ano em que a lei estava em pleno vigor. Em 1913 apenas $16 \%$ dos imigrantes eram de origem italiana, um distante terceiro lugar, atrás dos migrantes portugueses e espanhóis, enquanto os Estados Unidos da América surgiram nesses anos como o destino preferido dos emigrantes italianos para as Américas". ALIANO, David. Brazil through Italian Eyes: The Debate over Emigration to São Paulo during the 1920s. Torino, Rivista internazionale di studi sulle popolazioni di origine italiana nel mondo (Altreitalie), Number 31, p. 87-108, JulyDecember, 2005, p. 78.

${ }^{19}$ CENNI, Franco. Italianos no Brasil: "andiamo in Mérica". São Paulo, Editora da Universidade de São Paulo, 2003, p. 235.
} 


\section{A Exposição Universal de 1906 em Milão}

Desde a primeira exposição, organizada em 1851 na cidade de Londres, tais exibições caracterizavam-se em "comemorações do progresso" e "espetáculos da modernidade", de acordo com os preceitos positivistas bastante difundidos no período. Nestas exposições ficava óbvio o ufanismo das potencias tecnológicas imperiais, especialmente as europeias, e suas disputas por mercados e domínios colônias no período de plena expansão das políticas imperialistas ${ }^{20}$. Tanto a inauguração, em 1851, do Palácio de Cristal em Londres, quanto a invenção do telefone por Graham Bell na Filadélfia, em 1876, e a inauguração da Torre Eiffel em Paris, em 1889, figuravam como exemplos tangíveis e incontestáveis das grandezas nacionais e de afirmações de superioridades tecnológicas ${ }^{21}$.

Compreendemos o fenômeno das Exposições Universais como modelos do mundo geopolítico, visualmente apreensíveis, do período contemporâneo a estas representações. Nesta dinâmica de reproduções sociais, ao realizarem-se estas exposições, observamos reunidos em um mesmo espaço tanto as nações em expansão imperialistas europeias e os Estados Unidos emergentes, normalmente como anfitriões ou sustentando as posições de destaque, quanto os países emergentes da América Latina que buscavam sua ascensão no concerto mundial como promissoras fontes de matérias primas e, por fim, mesmo as regiões distantes (sob o prisma europeu) sob pleno regime imperialista. Ou seja, as Exposições Universais constituíam-se na mais condensada representação concreta do projeto de mundo eurocêntrico e capitalista. O mundo estava, agora, interconectado em redes de interdependência econômica (BARBUY, 1995). Conforme bem analisa Patrícia Mainardi,

The twentieth century term 'World's Fair' is, then, singularly inappropriate to describe these events. It was the idea of Progress wich distinguished these expositions, the very word in French preserves a didactic meaning from the fairs and bazaars of previous epochs. As in the Salon there were honors and medals, not cash prizes, to stress the intellectual rather than commercial aspects of production. ${ }^{22}$

A referida exposição Universal de Milão, nomeada oficialmente como L'Esposizione Internazionale del Sempione, surgiu com o desígnio da realização de uma grande exibição internacional relacionada às tecnologias de transporte. A ideia desta exposição surgiu para solenizar a inauguração da estrada de ferro que

${ }^{20}$ AVELLA, Ângelo Aniello. Itália e Brasil na Expo 2015. Universidade Estadual do Rio de Janeiro (UERJ), Revista GEO, n. 27, p. 353-361, 2015.

${ }^{21}$ BASSIGNANA, Paloma. Le feste popolari del capitalismo. Esposizioni d'industria e coscienza nazionale in Europa, 1798- 1911. Torino: Umberto Allemandi \& C., 1997.

${ }^{22}$ Em tradução livre: "O termo do século XX 'Feira Mundial' é, portanto, singularmente inadequado para descrever esses eventos. Foi a ideia de progresso que distinguiu essas exposições, a própria palavra em francês preserva um significado didático das feiras e bazares de épocas anteriores. Como no Salão havia honras e medalhas, não prêmios em dinheiro, para enfatizar a preferência intelectual em vez dos aspectos comerciais da produção." MAINARDI, Patricia. Arts and politics of the Second Empire: the universal expositions of 1855 and 1867. New Haven: Yale University Press, 1987, p. 17-18. 
estabelecia a ligação Paris-Milão, na ocasião da conclusão do Túnel do Simplon - um túnel ferroviário entre os Alpes que estabelecia a ligação entre a cidade de Briga, na Suíça, e a localidade de Iselle, na Itália.

A cidade de Miláo era considerada a capital econômica da Itália na primeira década do século XX, por isso, sediou a Exposição Universal de 1906, denominada também em alguns documentos de "A Grande Exposição do Trabalho". Com sua inauguração oficial fixada para o dia 28 de abril, esta exposição devia primitivamente compreender tão somente os meios de transporte, quer terrestres, quer marítimos e os novos e revolucionários transportes aéreos. Contudo, a direção da exposição optou por estender sucessivamente o seu programa a todos os ramos da atividade humana, e tornando-se então uma exposição universal. Encerrada em 31 de outubro, dois foram os locais escolhidos para a sua concretização: a Piaza d'Armi, vasta planície nos subúrbios da cidade, ligada por meio de um viaduto ao Parque do Simplon ${ }^{23}$, perfazendo um total de aproximadamente 250 acres, cerca de um milhão de metros quadrados, recebendo oficialmente 4.012 .777 visitantes $^{24}$.

As duas secções da exposição, ou seja, o Parque do Simplon e a Praça d'Armas, foram interconectadas por um amplo viaduto de 1.350 metros de comprimento, percorrido por uma estrada de ferro elétrica, onde cruzavam quatro trens de serviço $e$ ainda um pequeno trem auxiliar de reserva. Cada um destes trens transportava entre 280 a 300 passageiros, sucedendo-se suas viagens a cada 3 minutos. Desta forma, o fluxo entre as secções aproximava-se a 40 viagens por hora, com cerca de 60.000 pessoas. Em relação à dimensão das secções da exposição, a situada na Praça das Armas delineava-se muito mais vasta e complexa do que a situada no Parque do Simplon. Desembarcando-se dos trens elétricos na Praça d'Armas, em frente avistavase o vasto edifício destinado aos transportes marítimos, do qual elevava-se uma belíssima torre, isto é, um exato farol de 60 metros de altura, munido de um projetor elétrico que iluminava toda a área da exposição, assim como a cidade de Milão. Do topo deste farol era possível avistar os Alpes, com seu gelo eterno ${ }^{25}$.

As principais potências econômicas do período erigiram os maiores e mais centrais palácios de exposições. A França, em sua antiga e constante concorrência comercial e simbólica com a Inglaterra, e agora também com a Alemanha, com o investimento somado de 450.000 francos $^{26}$. A Inglaterra, buscando expor tanto seus principais artigos comerciais quanto os mais exóticos artigos advindos dos cantos mais remotos de seu império mundial, buscava uma demonstração simbólica de sua envergadura marítima e comercial, investindo mais de 10.000 liras.

Nesta disputa econômica e simbólica, dispendendo uma quantia de 350 marcos, a Alemanha, após aproximadamente quatro décadas de sua unificação, através de seu florescente parque industrial, despontava como potência concorrente da França e da

${ }^{23}$ A Federação, Porto Alegre, 10 de abril de 1906. Ano 1906 - Arquivo 00085. Disponível em http://memoria.bn.br/hdb/periodico.aspx. Acesso em 01/03/2016.

${ }^{24}$ Site oficial da Exposição Universal de 1906. Disponível em http://mi1906.ning.com. Acesso em 01/03/2016.

${ }^{25}$ A Federação, Porto Alegre, 16 de maio de 1906. Ano 1906 - Arquivo 00113. Disponível em http://memoria.bn.br/hdb/periodico.aspx. Acesso em 01/03/2016.

${ }^{26}$ A Federação, Porto Alegre, 10 de abril de 1906. Ano 1906 - Arquivo 00085. Disponível em http://memoria.bn.br/hdb/periodico.aspx. Acesso em 01/03/2016. 
Inglaterra. Além das três principais potências europeias e suas monumentais exposições, observamos também presenças modestas de países de menores envergaduras econômicas e políticas, com a exibição de seus principais artigos. A Bélgica edificou um pavilhão especial de 9.200 metros quadrados para a exposição de suas tecnologias ferroviárias. Dispôs também de 500 metros na galeria de automobilismo. A Suíça destinou um espaço de 1.700 metros para ferrovias e 250 metros especialmente para trilhos, 300 para automóveis, 625 para meteorologia e 440 para máquinas agrícolas.

A Turquia construiu um pavilhão de mais 150 metros na secção dos transportes por terra para a exposição da tecnologia empregada na estrada de ferro da Anatólia. Arquitetou também 150 metros para pesca e um quiosque de 36 metros quadrados reservado para a Dívida Pública Otomana. A China estabeleceu um pavilhão de 400 metros e o Japão tomou 135 metros para a pesca e 800 para as artes decorativas. A participação dos países orientais não atingidos pelas práticas de conquista imperialistas do século XIX na exposição nos parece motivada diretamente por uma experiência de demonstração de seus processos de Industrialização de sua econômica e de ocidentalização de sua política e cultura, especialmente no Japão após a Revolução Meijii ${ }^{27}$.

Entre as extensas galerias dos transportes, do automobilismo, da marinha, da agricultura, da arte moderna e dos amplos e suntuosos palácios das nações europeias, especialmente França, Alemanha, Áustria, Hungria, Inglaterra e Bélgica, erguia-se o grande Pavilhão da América Latina. Com desenho do célebre arquiteto Bonsi, sua bela cúpula destaca-se dos projetos arquitetônicos que o franqueavam. Após o comitê Executivo da Exposição conceder excepcionalmente o terreno gratuito, o Pavilhão da América Latina foi erigido devido à boa vontade e à concórdia dos cônsules do Sul e Centro-América estabelecidos em Milão.

Abrangendo uma área de cerca de 700 metros quadrados, o Pavilhão da América Latina, abrigando as exposições da Argentina, Chile, Uruguai, Peru, Guatemala, Costa Rica e São Domingos e de um único estado brasileiro - o Rio Grande do Sul. A mobília e a decoração interna do pavilhão ficaram ao encargo da Fábrica Italiana de Móveis de Milão que, através de seu diretor, Heitor Drisaldi, no anseio de manifestar sua simpatia e desejo de estender seus negócios a este continente, encarregou-se das referidas - especialmente no chamado Salão dos Presidentes - às suas expensas. Como peculiaridade do Pavilhão da América Latina, o Salão dos Presidentes reunia retratos, em tamanho natural, dos presidentes que regiam os destinos das repúblicas latino-americanas. Este salão era dedicado às recepções oficiais e, notadamente, à solene comemoração do IV centenário da morte de Cristóvão Colombo ${ }^{28}$. Do espaço ocupado pelo Pavilhão da América Latina, 136 metros foram dedicados à exposição do Rio Grande do $\mathrm{Sul}^{29}$. O contrato assinado para a participação do Rio Grande do Sul na Exposição Universal de 1906, que continha, em suas cláusulas tanto o espaço

\footnotetext{
27 Jornal A Federação, Porto Alegre, 10 de abril de 1906. Ano 1906 - Arquivo 00085. Disponível em http://memoria.bn.br/hdb/periodico.aspx. Acesso em 01/03/2016.

28 Jornal A Federação, Porto Alegre, 11 de abril de 1906. Ano 1906 - Arquivo 00086. Disponível em http://memoria.bn.br/hdb/periodico.aspx. Acesso em 01/03/2016.

${ }^{29}$ Jornal A Federação, Porto Alegre, 11 de abril de 1906. Ano 1906 - Arquivo 00086. Disponível em http://memoria.bn.br/hdb/periodico.aspx. Acesso em 01/03/2016.
} 
dedicado ao estado dentro do Pavilhão da América Latina quanto a exposição e participação nas competições de qualidade e mérito, custou 6.800 francos ao governo de Borges de Medeiros, sendo pagos em 28 de fevereiro de 1906. Conforme carta de Bruno Chaves: "pedi enviar-me a somma de sete mil francos em ordem telegráfica. $\mathrm{O}$ preço total é de 6.800 francos, eu falei em sete mil para mais clareza e economia na transmissão do telegramma. O resto da somma servirá para pagamento dos telegrammas, restam pequenas despesas insignificantes." 30

Compreendemos que, tanto nações como França, Inglaterra e Alemanha - atores centrais do teatro político europeu - quanto os países latino-americanos ou mesmo países orientais, como Turquia, China e Japão, continham objetivos particulares dentro de suas dinâmicas comerciais, econômicas, políticas e simbólicas. Contudo, nosso principal questionamento volta-se ao fato de que, dentro do universo de estados que compunham a federação brasileira, ou mesmo a nação, unicamente o Rio Grande do Sul participou da Exposição Universal, como foi amplamente publicizado pelo governo de Borges de Medeiros "É de lastimar porém, que o Brasil, por circumstancias que não me é dado analysar, não se faça officialmente representar n'este grande certâmen, onde a maior parte das nações apresentarão o que tem de melhor em producções indutriaes e naturaes." ${ }^{31}$

Deste modo, para a compreensão dos motivos do governo Borges de Medeiros a promover a participação do Rio Grande do Sul na Exposição Universal de 1906, é necessário estabelecer a articulação entre processos distintos em suas conjunturas, $e$ distantes geograficamente. Entretanto, ligados pela dinâmica do deslocamento populacional gerado pela emigração italiana para o Brasil estão: a realidade encontrada pelo imigrante destinado à lavoura de café em substituição ao braço escravo em São Paulo, os debates realizados entre defensores e detratores da emigração em solo italiano e o estabelecimento do Decreto Prinetti, que influenciou no fluxo populacional italiano pra o Brasil, inclusive para o Rio Grande do Sul.

\section{Vida e propaganda dos imigrantes italianos no Rio Grande do Sul}

Apontamos a participação do Rio Grande do Sul na Exposição Universal de Milão de 1906 como uma forma de propagandear as qualidades da terra, do clima e das leis do estado, apropriadas para a emigração de italianos. Entretanto, mais do que isto, buscava apresentar a situação dos italianos estabelecidos em solo rio-grandense, buscando informar que os mais de 300 mil ítalo-brasileiros nele estabelecidos se encontravam em ótima situação econômica e social.

Mas que, em todo o caso, a emigração para o Rio Grande do Sul, graças a salubridade do clima, a feracidade do solo e as sabias e liberalíssimas leis é cousa bem diversa $e$

\footnotetext{
${ }^{30}$ Instituto Histórico e Geográfico do Rio Grande do Sul. Arquivo Borges de Medeiros. CHAVES, Bruno. Carta. Roma, Itália. 14/2/1906. 2 folhas. Documento 12148.

Descritos: Política internacional, Partido Republicano Rio-Grandense.

${ }^{31}$ Instituto Histórico e Geográfico do Rio Grande do Sul. Arquivo Borges de Medeiros. CHAVES, Bruno. Carta. Roma, Itália. 14/2/1906. 2 folhas. Documento 12148.

Descritos: Política internacional, Partido Republicano Rio-Grandense.
} 
grandemente proveitosa, tanto para o emigrante como para o Estado que o acolhe bastando para prova recordar que existem no Estado 300 mil italianos, proprietários quase todos das terras que cultivam, de prédios e bens que lhes proporcionam boa renda, ou exercendo commercio $e$ indústria remuneradores. ${ }^{32}$

Conforme percebemos na carta de Murillo Furtado, designado por Borges de Medeiros ao cônsul do Rio Grande do Sul na referida exposição, onde este relata a visita do Ministro do Exterior Italiano, Cav. Fittoni, a real intenção da participação do estado na Exposição Universal delineava-se no conhecimento do estado sulino, da situação dos emigrantes italianos e o consequente cancelamento do Decreto Prinetti, colaborando assim para a retomada e incremento do fluxo de emigrantes italianos para o estado rio-grandense.

O ministro Fittoni prometeu estudar seriamente o problema magno e complexo da emigração e fazer tudo o possível para conseguir a revogação do Decreto Prinetti, pois está convencido de que os Estados do Brazil, autônomos como são, offerecem vantagens diversas aos colonos e que o Rio Grande do Sul, por suas condições especiais de clima, situação geographica, riquezas naturaes e sabias leis que o regem, está destinado a receber a maior parte da corrente emigratória futura. Oxalá se torne em realidade sua promessa... $^{33}$

Nesse contexto, parece relevante também destacar a compreensão de que a participação do Rio Grande do Sul como único estado brasileiro na Exposição de Milão significava uma tentativa de expor e defender os interesses e particularidades da imigração para o estado sulino em oposição aos estados onde os imigrantes sofreriam os divulgados maus tratos.

Entre as inúmeras diferenças que situavam o PRR (Partido Republicano RioGrandense) e o PRP (Partido Republicano Paulista) em posições opostas na política nacional $^{34}$, encontrava-se a crítica ao sentido da imigração subsidiada de europeus

\footnotetext{
32 Jornal A Federação, Porto Alegre, 15 de outubro de 1906. Ano 1906 - Arquivo 00239. Disponível em http://memoria.bn.br/hdb/periodico.aspx. Acesso em 01/03/2016.

${ }^{33}$ Instituto Histórico e Geográfico do Rio Grande do Sul. Arquivo Borges de Medeiros. FURTADO, Murillo. Carta. Milão, Itália. 23/9/1906. 2 folhas. Documento 12143. Grifo nosso. Descritos: Política internacional, Partido Republicano Rio-Grandense.

${ }^{34}$ Sobre as disputas entre o PRR e PRP, ver HERRLEIN JR., Ronaldo; DIAS, Adriana. Trabalho e indústria na Primeira República. In: TARGA, Luiz Roberto Pecoits (org). Gaúchos e paulistas: dez escritos de história regional comparada. Porto Alegre: FEE, 1996, p. 141-180. LOVE, Joseph. O regionalismo gaúcho e as origens da Revolução de 1930. São Paulo: Perspectiva, 1975. OLIVEIRA, Tiago Bernardon de. Mobilização operária na República excludente: um estudo comparativo da relação entre Estado e movimento operário nos casos de São Paulo, Minas Gerais e Rio Grande do Sul nas duas primeiras décadas do século XX. Porto Alegre: Dissertação de Mestrado em História/UFRGS, 2003. RIBEIRO, Maria Thereza Rosa. Vicissitudes da Questão Social no Brasil: liberalismo versus
} 
para os cafezais paulistas. Tanto Júlio de Castilhos quanto Borges de Medeiros eram abertamente contrários a política de imigração subsidiada pelo Estado realizada em São Paulo, perpetrada com fundos públicos e que destinavam-se unicamente aos interesses privados dos grandes latifundiários cafeicultores. Situação esta que resultava na exploração sem oportunidades aos imigrantes, que viriam para o Brasil na condição de mão de obra para substituir os cativos libertos, nas mesmas funções e em condições análogas.

Em contraponto a esta política de imigração subsidiada, Castilhos e Medeiros defendiam uma política de imigração espontânea estabelecida ainda no período imperial: ao invés de importar braços para os latifúndios monocultores como mão de obra semiescravizada, no Rio Grande do Sul o imigrante encontrava condições, através da concessão de terras por meio de créditos facilitados, para fixar-se à terra na condição de camponeses proprietários de minifúndios dedicados à policultura $e$ trabalhados pela mão de obra familiar. De acordo com a ideologia positivista dominante no Rio Grande do Sul durante o período da República Velha, esta condição viria a ter consequências em termos de desenvolvimentos sociais $e$ econômicos nos demais setores da economia.

Nesse contexto, a participação do estado gaúcho na Exposição Universal de 1906 deve ser compreendida como uma tentativa de diferenciar o sentido da imigração para o eixo do centro-oeste, dedicado à produção cafeeira, da imigração baseada na colonização, praticada no Rio Grande do Sul. Este fator possibilita um entendimento de maior consistência aos atos e investimentos do Rio Grande do Sul na Exposição.

Para concretizar esta ambição, o governo de Borges de Medeiros buscou expor as características do clima, da terra, das leis no Estado. Também procurou demostrar o desenvolvimento agrícola, comercial $e$ industrial $e$ a contribuição do emigrante italiano nestas áreas, além de expor as condições econômicas e sociais destes indivíduos em solo rio-grandense.

Esse contexto fica mais claro quando analisamos a reportagem de 15 de outubro de 1906 do órgão oficial do PRR, que ilustra os resultados dos trabalhos do professor Lessa Paranhos, do tenente Guilherme Chaves Moutier e do designado cônsul do Rio Grande do Sul, Murillo Furtado, comissários responsáveis pela exposição do Rio Grande do Sul. "Tem os nossos commissarios desenvolvido uma propaganda insistente, captando a attenção dos visitantes de nosso salão, em Milão, com as informações minunciosas com que os acompanham, elucidando os sobre o que nos interessa, especialmente para o problema da emigração." 35

O uso de Exposições Universais para propagandear as condições de vida no Brasil visando o estimulo da imigração não ilustra-se como uma inovação. A estreia como participante oficial nas Exposições Universais ocorreu em 1862, na cidade de Londres. Fomentada principalmente pelo Imperador D. Pedro II, a participação brasileira buscava, por um lado, evidenciar o potencial agrícola e industrial, atraindo assim imigrantes e investidores, e, por outro, inserir o Brasil como um dos atores no

positivismo na passagem do trabalho escravo para o livre (1870-1905). São Paulo: Tese de Doutorado em Sociologia/USP, 1999.

35 Jornal A Federação, Porto Alegre, 15 de outubro de 1906. Ano 1906 - Arquivo 00239. Disponível em http://memoria.bn.br/hdb/periodico.aspx. Acesso em 01/03/2016. Grifo nosso. 
teatro das nações civilizadas ${ }^{36}$. O Brasil retorna ao circuito das Exposições Universais em 1889, em Paris. Novamente apoiado pelo Imperador D. Pedro II, somente alguns meses antes de sua deposição, a exposição brasileira buscava proporcionar aos países europeus e aos visitantes a visão de um Brasil rico em oportunidades de emprego $e$ terras férteis a serem cultivadas, aguardando os europeus dispostos a emigrar $e$ construir suas fortunas. Lembramos que esta participação e a tentativa de construção da imagem brasileira ocorreu no contexto de expansão da economia cafeicultora e na substituição do braço escravo, liberto no ano anterior ${ }^{37}$.

Tendo como representação máxima de sua exibição a inauguração da Torre Eiffel, a exposição de 1889, comemorativa do centenário da Revolução Francesa, teve relevante significado tanto para a França republicana quanto para o Brasil imperial. O Brasil, última monarquia do continente americano, fez-se representar por meio do Comitê Franco-Brasileiro formado especialmente por empresários e jornalistas. Ainda em 1887, o Imperador D. Pedro II apreciava as construções da Exposição, acompanhado pelo Diretor Geral de Obras, Georges Berger. O pavilhão dedicado ao Império do Brasil localizava-se ao lado de outros treze países americanos, especialmente Argentina e México, espaço que ficou conhecido como "rua dos países do sol' em alusão ao clima dos países tropicais e subtropicais.

Entretanto, a participação na Exposição Universal não contribuiu para a desconstrução das imagens estereotipadas que muitos europeus sustentavam sobre a América Latina. Com arquiteturas fantasiosas e, muitas vezes, infelizes, o pavilhão brasileiro deixou a impressão de uma "grande plantação", assim a Bolívia de uma "gigantesca mina". Por fim, a queda do Império do Brasil, poucos dias após o encerramento da Exposição, contribuiu para a fixação das imagens das "republiquetas de bananas e das ditaduras revolucionárias de carnaval"'88.

No entanto, neste momento nos interessa delinear os objetivos que nortearam a participação do Império Brasil na Exposição Universal de Paris, em 1889, para, de uma perspectiva comparada, tornar inteligível a participação do Rio Grande do Sul na Exposição de Milão, em 1906. Como primeiro ponto, apresentamos a busca tanto pela atração de investimentos estrangeiros como pelo desenvolvimento mercados para exportação dos gêneros agrícolas nacionais. A chegada à área da exibição destinada à América Latina e, especialmente, ao Brasil proporcionava o experimento de um mundo inter e subtropical, pleno e promissor em recursos e possibilidades naturais, recém integrado ao circuito econômico mundial, graças ao movimento capitalista industrializante e universal europeu. Possibilidades estas em muito despertadas pela presença do emigrante europeu - fator que nos leva ao segundo ponto de compreensão da participação brasileira.

Apesar de os emigrantes, em sua grande maioria, haverem deixados a Europa em situação de miséria, eram tratados como "heróis pioneiros", sendo atribuídos a eles os sucessos do desenvolvimento produtivo e econômico alcançado recentemente pela

\footnotetext{
${ }^{36}$ PESAVENTO, Sandra Jatahy. Exposições universais: espetáculos da modernidade do século XIX. São Paulo: Hucitec, 1997.

37 AVELLA, Ângelo Aniello. Itália e Brasil na Expo 2015. Universidade Estadual do Rio de Janeiro (UERJ), Revista GEO, n. 27, p. 353-361, 2015.

${ }^{38}$ BARBUY, Heloisa. O Brasil vai a Paris em 1889: um lugar na Exposição Universal. Anais do Museu Paulista. São Paulo. N. Sér. v.4 p. 211-261 jan./dez, 1996.
} 
América do imigrante. Este contexto é explicado pela visão também difundida de uma América, assim como de um Brasil ainda imperial, atrasado e carente, povoado por uma população indolente; entretanto, em processo de renovação pela cultura europeia trazida pelos imigrantes.

Assim, em pleno vigor da política imigrantista, procurava-se delinear o Brasil como um país atrativo ao capital estrangeiro e aberto aos imigrantes europeus. Construía-se a imagem do Brasil sobre o tripé do país promissor em recursos naturais/país aberto a emigração europeia/país da concretização dos sonhos. Para tanto, além do pavilhão dedicado ao Brasil, a publicação de obras e periódicos contribuíram para concretizar esta imagem. Conforme analisaremos, esta dinâmica foi copiada, para a Exposição de 1906, pelo Rio Grande do Sul.

Sob a direção do jornalista paranaense radicado na França, Frederico José de Santa-Anna Nery, foram publicadas duas obras especialmente concebidas para a Exposição. Em Le Brésil en 1889, Santa-Anna, auxiliado por especialistas de diversas áreas, apresentava vinte e cinco capítulos detalhando o Brasil desde o relevo, a hidrografia, a fauna e a flora, a climatologia e a mineralogia, passando pelas áreas da agricultura, do comércio, da indústria e das instituições bancárias, até a instrução pública, as ciências e as artes. Obviamente, dedicando especial atenção aos capítulos relativos ao trabalho escravo, ao trabalho livre e ao processo de imigração. Por sua vez, em Guide de I'émigrant au Brésil, Santa-Anna apresentava o país como uma terra rica, vasta e ainda não trabalhada, à espera da mão de obra europeia para trabalhá-la. Delineava o país como solução para europeus insatisfeitos com sua situação e dispostos a cruzar o Atlântico em busca da concretização de seus sonhos econômicos e sociais. Além disto, dirigiu, também, L'Amérique - jornal editado semanalmente de maio a novembro, período da Exposição ${ }^{39}$. Todos estes instrumentos foram reproduzidos pelo Rio Grande do Sul em 1906.

Através da exposição do contexto do estado sulino, visava-se realizar uma propaganda do cenário econômico, social e político do Rio Grande do Sul para, por um lado, convencer as autoridades italianas a revogarem qualquer forma de legislação que embaraçassem a emigração italiana para terras brasileiras e, por outro, atrair a população italiana que buscava a opção da emigração para as terras governadas por Borges de Medeiros. Uma propaganda feita com mapas e fotografias revelava a situação de milhares de italianos que atravessaram o Atlântico emigrando para viver em terras do Rio Grande do Sul. Essa estratégia propagandista buscava enfatizar a prosperidade econômica do estado $e$ o reconhecimento social em relação aos imigrantes italianos, concretizando não apenas o sonho da propriedade, assim como também da ascensão às atividades em casas de comércio e posse cargos públicos, mas, principalmente, a promessa para possíveis futuros emigrantes, de encontrarem no estado sulino "facilidades desde que aportam no Estado, e sabendo ainda que as nossas riquezas estão por explorar", como exposto no texto a seguir.

As explicações e informações ministradas suprehendem principalmente os próprios italianos, mais que os forasteiros. Aquelles, em grupos e com grande curiosidade, perguntam e

${ }^{39}$ BARBUY, Heloisa. O Brasil vai a Paris em 1889..., p. 213-216. 
reperguntam tudo, sobre tudo, principalmente, depois que ficam sabendo, admiradíssimos, que vivem no Rio Grande centenas de milhares de italianos, e que lhes são mostrados os mapas prhotographias e os dados acerca de tudo que concerne aos italianos. Verdadeira satisfacção revelam os ouvintes ao saberem da prosperidade dos colonos italianos no Rio Grande do Sul, proprietários em sua maior parte, possuindo grandes extensões de terra cultivada: de campo, casas de commércio, exercendo cargos públicos, electivos $e$ de nomeação, encontrando todas as facilidades desde que aportam no Estado, e sabendo ainda que as nossas riquezas estão por explorar. ${ }^{40}$

Aos italianos que visitavam a exposição do Rio Grande do Sul eram expostos dados detalhados acerca do desenvolvimento econômico e social dos compatriotas que escolheram a opção da emigração. Eram apresentadas as facilidades propostas pelo governo de Borges de Medeiros em relação ao transporte para o Estado, além das possibilidades de ganhos e lucros auferidos pelas lavouras das pequenas propriedades coloniais. Também eram apresentados dados relativos ao salário dos emigrantes que no Rio Grande do Sul se dedicavam ao trabalho operário industrial e a possibilidade de envolverem-se com empreendimentos comerciais e agroindustriais, além, é claro, da possibilidade de praticarem seus cultos e sua fé com liberdade. A citação a seguir é ilustrativa nesse sentido:

Ficam maravilhados (os italianos visitavam a exposição) com as noticias acerca do nosso clima, do preço dos salários do trabalhador industrial ou operário, dos lucros que entre nós proporciona qualquer lavoura, pequena que seja, qualquer pequena indústria, da segurança individual, da liberdade para qualquer trabalho como para professarem seu culto, das garantias de locomoção e da facilidade de transportes, etc., etc. $^{41}$

Semelhante estratégia de fomento do fluxo emigratório italiano através da Exposição Universal de 1906 foi empregada pelo governo da Argentina. Assim como Adolpho Rossi fora enviado para o Brasil em 1902 para realizar um detalhado relatório acerca das condições dos imigrantes ítalos aqui instalados, o repórter Luigi Bargini fora enviado pelo Corriere dela Sera, de Milão, à Argentina para examinar e divulgar a situação dos imigrados naquele país. Bargini, consciencioso observador, segundo confessavam os próprios jornais argentinos, formulou e documentou uma série de acusações sobre a colonização italiana na Argentina. Suas ácidas reportagens publicadas no período milanês percorreram não apenas os círculos argentinos $e$

\footnotetext{
40 Jornal A Federação, Porto Alegre, 3 de setembro de 1906. Ano 1906 - Arquivo 00206. Disponível em http://memoria.bn.br/hdb/periodico.aspx. Acesso em 01/03/2016.

${ }^{41}$ Jornal A Federação, Porto Alegre, 3 de setembro de 1906. Ano 1906 - Arquivo 00206. Disponível em http://memoria.bn.br/hdb/periodico.aspx. Acesso em 01/03/2016.
} 
italianos, mas também foram publicadas pelo Correio Paulistano, como em edição de 22 de junho de 1902, quando argumenta que "há mais de um milhão de italianos na Argentina e que mais da metade dos habitantes dão de sangue italiano. Os nossos braços são enviados para lá, quando lá mesmo milhares de braços pendem inertes no abandono da desesperação." 42

Frente a este mesmo contexto de propaganda visando o estimulo a imigração italiana, o governo Argentino utilizou-se do espaço denominado de Pavilhão de Italianos no Estrangeiro. Localizado na Piaza d'Armi e organizado pelo jornalista Alberto Manzi, redator do jornal Perseveranza, especialista nas colônias italianas, expôs, como o próprio nome já designa, as produções agropecuárias e industriais, assim como os avanços econômicos, sociais e culturais dos italianos emigrados de Paris, passando pela Eritréia até a América Latina. Neste ambiente, os enviados argentinos expuseram especialmente massas alimentícias, calçados, luvas, tecidos, chapéus, vinhos, licores, porcelanas, perfumarias, sabões, cigarros toscanos de marca Avanti!, móveis de madeira e ferro, velas, azeites, além de "uma grande quantidade de publicações, revistas e jornaes, entre as quaes se salienta La Patria degli Italiani, de propriedade de Cittadini e dirigida por Paroletti", além de um "enorme livro, creio que escripto pelo professor Franzoni e ricamente ilustrado, em que figuram interessante gravuras e diversos retratos de italianos enriquecidos na Argentina" ${ }^{43}$. Este referido espaço tornou-se para o governo da Argentina não apenas um comum instrumento de promoção comercial na busca de novos mercados para os gêneros coloniais italianos, mas um elo entre a Argentina e a Itália, com a intenção de estimular o fluxo de emigrantes ítalos para essa região em particular.

O ápice da promoção do Rio Grande do Sul em favor do cancelamento do Decreto Prinetti e da retomada do intenso fluxo de emigração ocorreu com a visita do Rei da Itália à exposição sulina. Conforme reportagem da $A$ Federação, de 29 de agosto de 1906, o comissário Guilherme Moutier destacou a preocupação dos governos de Júlio de Castilhos e Borges de Medeiros com o desenvolvimento das colônias de emigrantes italianos estabelecidos em solo rio-grandense, fazendo com que estas, em pequeno período de tempo, evoluíssem para centros urbanos de importante pungência econômica

Júlio de Castilhos só teve uma preoccupação: o desenvolvimento das colônias mediante medidas praticas, procurando facilitar todas as vias de communicação, fazendoas progredir economicamente, de modo que os antigos centros coloniais transformassem rapidamente em adiantadas cidades. No Estado do Rio Grande existem hoje mais de 300 mil italianos, todos proprietários de suas colônias, e que gosam dos direitos civis e políticos. O governo não poupa cousa alguma para demostrar a máxima proteção que

\footnotetext{
42 Jornal Correio Paulistano, São Paulo, 22 de junho de 1902. Ano 1902 - Arquivo 13949. Disponível em: http://memoria.bn.br/hdb/periodico.aspx. Acesso em 01/02/2017.

${ }^{43}$ Jornal Correio Paulistano, São Paulo, 06 de julho de 1906. Ano 1902 - Arquivo 15402. Disponível em http://memoria.bn.br/hdb/periodico.aspx. Acesso em 01/02/2017.
} 
concede aos colonos que ali chegam, aos quaes facilita todos os meios de, em poucos annos, terem garantido seu bem estar. $^{44}$

Com o desejo de conquistar a simpatia do Rei da Itália para o estabelecimento dos vínculos anteriores ao processo de emigração italiana e colonização rio-grandense, Guilherme Moutier destacou que Júlio de Castilhos batizou uma das colônias do Rio Grande do Sul de Garibaldi, em homenagem ao italiano Giuseppe Garibaldi, que compartilhou dos combates da Revolução Farroupilha ${ }^{45}$. A carta enviada de Milão pelo comissário Murillo Furtado, datada 12 de novembro de 1906, apresenta-nos maiores informações sobre a visita do Rei da Itália à exposição rio-grandense. Segundo Furtado, ao Rei da Itália, enquanto este analisava uma estátua de Giuseppe, Guilherme Moutier discorreu sobre Garibaldi e suas ações em favor da causa riograndense, que lhe renderam o status de herói estadual e homenageado com o nome de um dos principais núcleos coloniais ${ }^{46}$. Seguindo a visita, Sua Majestade italiana foi presenteada com um exemplar de luxo da obra "Un viaggio a Rio Grande del Sud"; obra essa concretizada sob a direção de Guilherme Moutier, com editoração dos jornalistas Carlo Parlagrecco e Vittorio Buccelli, apresentando fotografias, mapas e estatísticas relativas à agricultura, o comercio e à indústria do Rio Grande do Sul, com especial destaque à contribuição do emigrante italiano nestas áreas. Além do Rei italiano, esta obra também tornou-se presente para mais de 200 comissários estrangeiros que visitaram a exposição rio-grandense, além de ministros, senadores, aristocratas, intelectuais e jornalistas italianos.

Nosso Estado, por si só, obteve melhores recompensas que muitas das republicas americanas, taes como o Chile, Guatemala, S. Domingos e outras. Nos últimos dias de Exposição foram distribuidos muitos exemplares da excelente obra "un viaggio a Rio Grande del Sud" a pessoas gradas, tanto do meio commercial e industrial como do aristocrático $e$ intellectual. Tenho recebido inúmeros cartões e cartas de agradecimento de altos representantes da nobreza italiana, de

\footnotetext{
${ }^{44}$ Jornal A Federação, Porto Alegre, 29 de agosto de 1906. Ano 1906 - Arquivo 00202. Disponível em http://memoria.bn.br/hdb/periodico.aspx. Acesso em 01/03/2016.

45 "A uma d'estas colônias elle deu o nome de Garibaldi para que seja sempre lembrado que o intrépido italiano dedicou os mais bellos annos de sua mocidade em auxiliar a causa santa dos rio-grandenses, sedentos de bem estar e liberdade".

Jornal A Federação, Porto Alegre, 29 de agosto de 1906. Ano 1906 - Arquivo 00202. Disponível em http://memoria.bn.br/hdb/periodico.aspx. Acesso em 01/03/2016.

46"Ao próprio rei não vacilou Moutier em fallar sobre o Rio Grande do Sul e fazer breve e eloquente improviso alusivo ao heroe Garibaldi e suas primeiras campanhas na arte da guerra pela liberdade no território do Rio Grande. Aproveitou elle para isso o momento em que o rei se detinha a examinar o projecto em gesso da estatua de Garibaldi". A Federação, Porto Alegre, 17 de dezembro de 1906. Ano 1906 - Arquivo 00291. Disponível em http://memoria.bn.br/hdb/periodico.aspx. Acesso em 01/03/2016.
} 
diretores de estabelecimentos bancários, dos telegraphos $e$ correios, etc., aos quaes tenho enviado exemplares da obra. ${ }^{47}$

A obra publicada por Vittorio Buccelli, no início do século XX, fruto de sua viagem pelo Rio Grande do Sul e publicada em Milão no ano de 1906, no âmbito da Exposição Internacional, intitulada Un viaggio a Rio Grande del Sud, teve como principal propósito uma descrição da conjuntura recente do estado, avaliando a produção agrícola e manufatureira, pontos sobre a urbanística, o estado da saúde e da higiene, a conjuntura política, as circunstâncias culturais e de instrução relativas à imigração, com o objetivo final a promoção do fluxo de imigrantes para a colonização.

Sobre a trajetória de Vittorio Buccelli, este esteve à frente do executivo da cidade de Nizza Monferrato, na província de Asti, na região de Piemento. Em 1904 fora eleito para a Câmara dos Deputados italiana, sendo reconduzido ao cargo por três legislaturas. Com inclinações políticas esquerdistas, suas principais preocupações orbitavam em torno das questões agrárias, fato que proporciona a compreensão sobre as motivações que fizeram Buccelli envolver-se de maneira específica sobre a realidade da imigração sul-riograndense e a colonização baseada no sistema de pequenas propriedades. Na conjuntura dos debates acerca da imigração, Buccelli apresentava-se como um constante oponente em relação aos detratores do Brasil e dos possíveis aspectos positivos do deslocamento para o solo brasileiro.

Reconhecemos o caráter da obra, ou mesmo os vínculos políticos estabelecidos por Buccelli. O então político italiano empreendeu uma viagem pelo estado a convite de Borges de Medeiros e do Partido Republicano Rio-Grandense, o que qualifica uma interlocução do PRR com políticos italianos favoráveis ao processo imigratório. Fato este que torna inteligível o marcante aspecto laudatório da obra em relação ao Estado $e$ o processo de imigração e colonização por este dirigido. Contudo, estes fatores não desqualificam o texto ou mesmo apresentam Buccelli como um simples jornalista a serviço do PRR e de Borges de Medeiros.

Un viaggio a Rio Grande del Sud não limita-se ao seu efeito propagandístico para a atração de emigrantes em potencial que demostrassem interesse em deslocar-se para o estado. Todavia, a obra torna-se fundamental para a compreensão da polarização entre defensores e detratores do processo de imigração italiana, bem como expressar uma das visões difundidas na península itálica acerca da imigração $e$ das terras brasileiras $e$ as ações do governo rio-grandense para alterar esta imagem, além dos vínculos entre Borges de Medeiros e os políticos italianos favoráveis à imigração.

Compreendendo que as discussões entre defensores e detratores da emigração peninsular para o Brasil era plenamente conhecida pelo governo do PRR, conforme nos demostra o editorial do periódico A Federação de 15 de outubro de 1906 - "Os que tem inscripto contra a emigração para o Brasil, ou fizeram intencionalmente falseando os factos por motivos que não denunciava ou apenas muito superficial $e$

\footnotetext{
${ }^{47}$ Instituto Histórico e Geográfico do Rio Grande do Sul. Arquivo Borges de Medeiros. FURTADO, Murillo. Carta. Milão, Itália. 12/11/1906. 2 folhas. Documento 12144.
} 
erradamente conheciam o problema." 48 - a exposição rio-grandense buscava tornar o estado e seu contexto econômico, político, social e cultural mais conhecido entre os italianos com a finalidade de alterar o valor concedido a este na Itália.

Tenho recebido também muitos cartões, pedindo exemplares d'esse livro e muitos são as informações que meus colegas e eu temos prestado a aquelles que já se decidiram a partir para o Brazil, em demanda do Rio Grande do Sul, que ameaça agora ser melhor conhecido pelos italianos e ter outro valor. Aos 200 e tantos comissários estrangeiros, que aqui estiveram, representando quase todas as nações do mundo, foram também distribuídos exemplares, bem como aos senadores e ministros que acompanharam M. M. os Reis da Itália, na visita que fizeram a Exposição em outubro ultimo. $^{49}$

Mesmo que a medida de suspensão das partidas subvencionadas, implementada pela Itália, não tivesse uma relação direta com o Rio Grande do Sul e, sim, com o contexto do imigrante italiano em São Paulo, ela confirmava uma imagem e um juízo bastante negativo do Brasil, não como "el paese della cucagna", de abundância, da propriedade da terra e da ascensão social, mas, sim, da exploração, dos maus-tratos, se não da escravidão. Tanto a obra de Buccelli, quanto a exposição buscavam apresentar o Brasil, ou essencialmente o Rio Grande do Sul, como uma terra de igualdade, de oportunidades e materializações de sonhos, proporcionando uma crítica clara à visão construída pelos detratores da emigração da realidade brasileira e do Rio Grande do Sul que, para o governo Borges de Medeiros, era corrompida e advinda da ignorância ou mesmo da calúnia dos jornalistas, intelectuais e políticos italianos. Por fim, para encerrar a visita realizada em 30 de abril pelo Rei italiano, à sua esposa, agradecendo a visita Real, foi oferecido, em nome da América Latina, um buquê de flores naturais. "Ao proprio Rei não vacillou Moutier falar sobre o Rio Grande do Sul e fazer uma breve allusão a Garibaldi e seus primeiros passos na arte da Guerra, ensaiados em território rio-grandense". ${ }^{50}$

S. M. ouviu-o attentamente e prometteu ler a obra que lhe era offerecida. Havendo o Rei muito se interessado pela nossa colecção de pedras, Moutier, com um d'aquelles rasgos de gentileza que tanto o recommenda moffereceu visitante uma das pedras (uma grande amethista) que mais the havia

\footnotetext{
${ }^{48}$ Jornal A Federação, Porto Alegre, 15 de outubro de 1906. Ano 1906 - Arquivo 00239. Disponível em: http://memoria.bn.br/hdb/periodico.aspx. Acesso em: $1^{\circ}$ março. 2016.

${ }^{49}$ Instituto Histórico e Geográfico do Rio Grande do Sul. Arquivo Borges de Medeiros. FURTADO, Murillo. Carta. Milão, Itália. 12/11/1906. 2 folhas. Documento 12144. Descritos: Política internacional, Partido Republicano Rio-Grandese.

${ }^{50}$ Instituto Histórico e Geográfico do Rio Grande do Sul. Arquivo Borges de Medeiros. FURTADO, Murillo. Carta. Milão, Itália. 12/11/1906. 2 folhas. Documento 12144. Descritos: Política internacional, Partido Republicano Rio-Grandense.
} 
agradado. Como era de esperar, S. M. não acceitou, mas confessou-se penhoradíssimo. ${ }^{51}$

Quanto ao Rei, após este demonstrar curiosidade e interesse em uma exposição de mármores e outros minerais de valor, além de uma rica coleção de madeiras de lei, fora-lhe oferecida como presente uma ametista que havia lhe agradado, presente por ele recusado. Entretanto, conforme as palavras de Murillo Furtado, o objetivo maior da exposição parecia ter sido alcançado, ou seja, uma possível revogação do Decreto Prinetti ${ }^{52}$. "Eu provejo nisso tudo a revogação do celebre Decreto Prinetti" ${ }^{53}$.

\section{Enfim...}

Podemos dizer que, seja evocando passado e raízes em comum através da figura de Giuseppe Garibaldi, ou através dos comentários sobre o contexto social, econômico e político do Rio Grande do Sul ou, principalmente, da propaganda das condições adquiridas pelos emigrantes italianos que atravessaram o Atlântico rumo às terras rio-grandenses em busca da concretização de seus sonhos na propriedade da terra, da prosperidade na atividade comercial ou na fortuna da indústria, observamos uma interessante dinâmica na participação do Rio Grande do Sul em L'Esposizione Internazionale del Sempione.

A referida exposição tornou-se para o governo e o estado do Rio Grande do Sul não apenas uma simples ferramenta de promoção comercial na busca de novos mercados para os gêneros nele produzidos, mas um elo entre o estado sulino e a Itália, com a intenção de promover a revogação das restrições impostas pelo governo italiano à emigração e, com isso, estimular o fluxo de emigrantes ítalos para essa região em particular.

Compreendemos que, para além da dimensão econômica, houve, aliada a esta, uma estratégia de propaganda do Estado e um interesse político de revogar o Decreto Prinetti, estabelecido naquele período na Itália e que estaria dificultando a emigração subvencionada de italianos para o Brasil. Percebemos que os produtos expostos possuíam grande identificação com os gêneros agrícolas e industriais particularmente produzidos na denominada região colonial italiana. A referida exposição propunha também propagandear a filosofia política do governo de então, Borges de Medeiros, em sua dimensão positivista, principalmente em torno do regramento e controle social, da centralidade do estado nos assuntos econômicos e de configuração da propriedade da terra (via colonização dirigida), bem como do incentivo à economia familiar e às pequenas indústrias (agroindústrias).

51 Jornal A Federação, Porto Alegre, 17 de dezembro de 1906. Ano 1906 - Arquivo 00291. Disponível em http://memoria.bn.br/hdb/periodico.aspx. Acesso em 01/03/2016.

52 "Como é de seus hábitos, o rei d'Italia não acceitou, confessando-se penhoradíssimo. Estres factos parecem indicar a previsão de ser revogado o celebre decreto Prinetti, contrário a imigração para o Brasil".A Federação, Porto Alegre, 17 de dezembro de 1906. Ano 1906 - Arquivo 00291. Disponível em http://memoria.bn.br/hdb/periodico.aspx. Acesso em 01/03/2016.

${ }^{53}$ Instituto Histórico e Geográfico do Rio Grande do Sul. Arquivo Borges de Medeiros. FURTADO, Murillo. Carta. Milão, Itália. 12/11/1906. 2 folhas. Documento 12144. Descritos: Política internacional, Partido Republicano Rio-Grandense. 
A revogação do Decreto Prinetti era entendida pela esfera pública rio-grandense como fundamental aos interesses do povoamento e colonização, bem como de sua consequente, a produção de alimentos e os seus processos agroindustriais. $\mathrm{O}$ intenso fluxo de emigrantes italianos direcionados para a Argentina e outros países do continente americano, além de propiciar o desenvolvimento econômico desses territórios, poderia servir de atração emigratória para os imigrantes já estabelecidos no estado.

Desse modo, percebemos que houve um grande investimento de estado, no caso, o do Rio Grande do Sul, por ocasião da referida exposição, bem como buscou-se transnacionalizar processos produtivos e identitários, viabilizar uma contrapropaganda para fazer frente à existente na Itália daquele período, a qual acusava os maus tratos $e$ as condições precárias dos imigrantes, principalmente nas zonas cafeeiras.

\section{$\operatorname{son} 2$}

\section{RESUMO}

Buscamos analisar as narrativas, discursos $e$ debates suscitados entre defensores e detratores do processo de imigração italiana para o Brasil na primeira década do século XX, assim como suas respectivas consequências da legislação, em especial o Decreto Prinetti, que promoviam ou restringiam o deslocamento populacional transatlântico ítalo-brasileiros. Neste contexto, delineamos a participação do Rio Grande do Sul na L'Esposizione Internazionale del Sempione, na Itália em 1906, não unicamente como um espaço de criação de vínculos comercias, mas essencialmente como uma ferramenta para estabelecer um elo entre o estado sulino e a Itália, com a intenção de propagandear a situação dos imigrantes italianos no Estado, com o intuito da revogação das restrições impostas pelo governo italiano à emigração e estimular o fluxo de emigrantes ítalos para essa região em particular, que neste período tornara-se um destino preterido em favor dos EUA e da Argentina.

Palavras Chave: Decreto Prinetti; Exposição Universal de Milão; Imigração.

\begin{abstract}
This article analyzes the narratives, discourses and debates that have arisen between defenders and detractors of the Italian immigration process for Brazil in the first decade of the twentieth century, as well as their respective consequences of legislation, especially the Prinetti Decree, which promoted or restricted transatlantic population displacement Italo-Brazilians. In this context, we explain the participation of Rio Grande do Sul in L'Esposizione Internazionale del Sempione in Italy in 1906, not only as a space for the creation of commercial ties, but essentially as a tool to establish a link between the southern state and the Italy, with the intention of propagandizing the situation of the Italian immigrants in the State, with the intention of revoking the restrictions imposed by the Italian government on the emigration and to stimulate the flow of Italic emigrants to that particular region, that in that period had become a destiny deprived In favor of the USA and Argentina.
\end{abstract}

Keywords: Prinetti Decree; 1906 World Exposition; Immigration.

Artigo recebido em 07 fev. 2017.

Aprovado em 18 jun. 2018. 